\title{
Study on Microstructure and Properties of the UV Curing Acrylic Epoxy/SiO 2 Nanocomposite Coating
}

\author{
Ngoc Linh Nguyen $\mathbb{D}^{1,2}$ Thi My Linh Dang $\mathbb{D}^{3},{ }^{3}$ Tuan Anh Nguyen $\mathbb{D}^{3},{ }^{3}$ Hoang Thu Ha $\mathbb{D},{ }^{4}$ \\ and Thien Vuong Nguyen $\mathbb{D}^{1,3}$
}

${ }^{1}$ Graduate University of Science and Technology, VAST, 18 Hoang Quoc Viet, Cau Giay, Hanoi, Vietnam

${ }^{2}$ Faculty of Pharmacy, Thanh Do University, Kim Chung, Hoai Duc, Hanoi, Vietnam

${ }^{3}$ Institute for Tropical Technology, VAST, 18 Hoang Quoc Viet, Cau Giay, Hanoi, Vietnam

${ }^{4}$ VNU-University of Education, Vietnam National University, Hanoi, Vietnam

Correspondence should be addressed to Hoang Thu Ha; hoangthuhavnuued@gmail.com

and Thien Vuong Nguyen; vuongvast@gmail.com

Received 22 June 2021; Revised 12 August 2021; Accepted 1 October 2021; Published 29 October 2021

Academic Editor: Ester Vazquez

Copyright (C) 2021 Ngoc Linh Nguyen et al. This is an open access article distributed under the Creative Commons Attribution License, which permits unrestricted use, distribution, and reproduction in any medium, provided the original work is properly cited.

\begin{abstract}
This study is aimed at exploring the effects of $\mathrm{SiO}_{2}$ nanoparticles on the crosslinking and mechanical and thermal properties of UV curing acrylic epoxy coating. The curing polymerization process and thermal and mechanical properties of UV-curable acrylate epoxy system have been evaluated with or without the presence of $\mathrm{SiO}_{2}$ nanoparticles. To fabricate the UV curing acrylic epoxy $/ \mathrm{SiO}_{2}$ nanocomposite coating, nano- $\mathrm{SiO}_{2}$ particles $(0.5-5 \mathrm{wt} . \%$ by weight of resin) were added in the photocurable system using sonication for $3 \mathrm{~h}$. Various techniques for characterization have been used, such as FESEM (field emission scanning electron microscope), FTIR (Fourier-transform infrared spectroscopy), TGA (thermogravimetry analysis), gel fraction, and swelling degree analyses. FESEM data indicated that at the content of $2.5 \mathrm{wt} . \%$, nanosilica was homogeneously dispersed in the coating procedure. However, once added $5 \mathrm{wt} . \%$, large aggregation portions were found inside the coating matrices. Surprisingly, nano- $\mathrm{SiO}_{2}$ could play dual roles, as both UV absorbers and nanoreinforcers, in this nanocomposite coating. Besides, data from FTIR, gel fraction, and swelling degree analyses confirmed the role of $\mathrm{SiO}_{2}$ nanoparticles as UV absorbers that reduced the conversion performance of acrylate double bonds, thus increased slightly the swelling degree of coating. In addition, incorporation of $\mathrm{SiO}_{2}$ nanoparticles (as nanofillers, at content of $2.5 \mathrm{wt} . \%$ ) in the polymer matrix enhanced significantly the abrasion resistance and thermal stability of the coating, by $60 \%$ (from 98.3 to 158.4 lite $/ \mathrm{mil}$ ) and $9^{\circ} \mathrm{C}$ (from $348^{\circ} \mathrm{C}$ to $357^{\circ} \mathrm{C}$ ), respectively.
\end{abstract}

\section{Introduction}

As can be processed at room temperature and organic solventfree, acrylate resin-based UV curing paints exhibit many advantages, such as transparency, moisture resistance, chemical resistance, and environmental friendly. As reported, they have been widely applied to various finish surfaces, such as steel or wooden floors [1-5]. However, the main disadvantage of this resin system is the high curing shrinkage (up to $15 \%$ ) $[6,7]$. Its shrinkage could be enhanced by three pathways such as the following: (i) by selecting components (with suitable structure), (ii) by increasing the curing density, and (iii) by using fillers [7-12].

Nowadays, nanomaterials and nanotechnologies are extensively developed for emerging applications, such as nanoenergetic composites [13], propellant composite formulation [14], protein immobilization [15], microbial fuel cell [16], and microbial electrolysis cell [17]. In case of the coating technology, incorporation of inorganic nanoparticles, such as $\mathrm{SiO}_{2}$ [18-20], $\mathrm{ZnO}$ [21-23], $\mathrm{TiO}_{2}$ [24-26], $\mathrm{Fe}_{3} \mathrm{O}_{4}$ [27], and 
nanohybrids [28-30] into the formulation of polymer materials, offers the significant enhancement of their properties when used for coating. By adding nanosilica in the coating process, the mechanical, thermal, and anticorrosion characteristics of the organic coatings were critically enhanced [31-36]. Nano- $\mathrm{SiO}_{2}$ was employed for both superhydrophobicity coating [37-41] and hydrophilic coating [42].

However, the addition of nanoparticles (as nanofillers) can affect the curing reaction of thermoset resin systems depending on the nature and content of the nanoparticles. In the case of the epoxy matrix, $\mathrm{Fe}_{3} \mathrm{O}_{4}$ nanoparticles can act as a bridging link molecule, thereby reducing the total free mass and increasing the crosslinking density $[43,44]$. In this direction, to study the healing dynamics of the epoxy/amine system, $\mathrm{Fe}_{3} \mathrm{O}_{4}$ nanoparticles were used as nanocontainers for loading the acid functional groups [45], amino functional groups $[46,47]$, or hydroxyl functional groups $[46,48]$. The previous reported publications mentioned that the reaction between acidic groups and amine groups of curing agent can deactivate the hardener [45]. And the existence of hydroxyl and amine groups might boost the epoxy groups. It resulted to an increase in the content of thermal curing [46]. For example, Yari et al. investigated that nanosilica caused to an incomplete curing procedure of the acrylic melamine clearcoat, suggesting to a lower crosslinked density, as compared with the pure clearcoat and improved weathering capacity. It might be assumed that nano- $\mathrm{SiO}_{2}$ absorbed the harmful incident UV rays, protecting the clearcoat against weathering degradation [49]. In our reported reviews [50], when conducting the curing reaction of acrylic polyols with isocyanate, we found that $\mathrm{SiO}_{2}$ nanoparticles involved in reaction with isocyanate group to form a tight inorganic-organic hybrid structure. For UV curing systems, the degree of influence of additives depends not only on the content but also on their ability to absorb UV rays and photocatalytic activity. For $\mathrm{Fe}_{3} \mathrm{O}_{4}$-Ag hybrid nanoparticles, despite a strong UV absorption, their low content (0.1 wt.\%) might not significantly affect the kinetics of curing reaction [51]. The organic UV absorber T384 reduced the efficiency of double bonds while nanoparticles absorb UV anatas- $\mathrm{TiO}_{2}$ and $\mathrm{ZnO}$ increased the conversion of the acrylate groups of the system due to strong photocatalytic activity [52].

Although polymers $/ \mathrm{SiO}_{2}$ nanocomposites have been reported intensively in the literature, effect of nanoparticles on the kinetics of photo-curing process for UV curing acrylic epoxy resin system has not been well clarified. In this work, the photo-crosslinking polymerization process of the system of acrylate epoxy resin and 1.6 hexanediol diacrylate diluent in the presence of $\mathrm{SiO}_{2}$ nanoparticles has been evaluated by using various techniques, such as the quantitative infrared analysis, relative hardness, gel fraction, and swelling degree measurements. In addition, the effect of $\mathrm{SiO}_{2}$ nanoparticles on the mechanical and thermal properties of nanocomposite coating is evaluated.

\section{Materials and Methods}

2.1. Materials. All the chemicals were ordered from SigmaAldrich, such as Bisphenol A glycerolate dimethacrylate (BGDM) and 1,6-hecxanediol diacrylate $80 \%$ (HDDA). The photoinitiator 1-hydroxy-cyclohexyl-phenyl-ketone, Irgacure 184 (I.184) was obtained from CIBA (Merck). Their structures are shown in Figure 1. The used $\mathrm{SiO}_{2}$ nanoparticles were selfsynthesized according to the method presented in our previous article [50].

2.2. Preparation of Nanocomposite Coating. $\mathrm{SiO}_{2}$ nanoparticles, at the contents from 0.5 to $5 \mathrm{wt} . \%$, were firstly dispersed in HDDA by using a TPC-25 supersonic bath (Switzerland) for $3 \mathrm{~h}$; then, these mixtures were mixed with E284 and I.184 by stirring in the Ika RW16 Basic Mixer (England) for $30 \mathrm{~min}$. The ratio of E284:HDDA : I.184 was $55: 45: 3$.

Coatings with the thickness of $\sim 25 \mu \mathrm{m}$ were prepared on $\mathrm{KBr}$ pellets for IR spectral analysis, on Teflon sheets with the size of $100 \times 100 \times 10 \mathrm{~mm}$ for UV-Vis spectral, gel fraction, swelling degree, and FESEM analyses, on glass plates with the size of $100 \times 100 \times 2 \mathrm{~mm}$ for relative hardness and abrasion resistance tests by using a Quadruple Film Applicator Model 360. The coating process was applied for an UV radiation of a medium-pressure mercury lamp $\left(250 \mathrm{~mW} / \mathrm{cm}^{2}\right)$ at $25^{\circ} \mathrm{C}$ in an UV device, model F300S, USA. The product was conducted various times under the light with a web rate ranged of $5-40 \mathrm{~m} / \mathrm{s}$.

\subsection{Methods for Characterization of Coatings}

2.3.1. IR Spectral Analysis. Changes of IR absorption band at $983 \mathrm{~cm}^{-1}$ (=CH stretching) assigning to acrylate double bonds during the crosslinking reaction were quantitatively studied by using a FTIR spectroscopy NEXUS 670 from Nicolet. Experiments are carried out at the same position of each sample and after various time of UV exposure [51]. Benzene ring at $1510 \mathrm{~cm}^{-1}$ was selected as a band to eliminate the changes in the coating thickness.

The optical density $(D)$ of groups was estimated by the following formula:

$$
D=\log \left(\frac{I_{0}}{I}\right)=\log \left[1+\frac{H}{(100-U)}\right]
$$

The relationship between $I_{0}$ and $I$ with $H$ and $U$ is shown in Figure 2 where $H$ and $U$ were calculated by using the software of FTIR spectroscopy.

Remaining acrylate group was calculated as follows:

Remaining acrylate group $(\%)=\left[\frac{\left(D_{983 \mathrm{~cm}^{-1}} / D_{1510 \mathrm{~cm}^{-1}}\right)_{t}}{\left(D_{983 \mathrm{~cm}^{-1}} / D_{1510 \mathrm{~cm}^{-1}}\right)_{0}}\right] \times 100$

where $D_{0}$ and $D_{t}$ are the optical densities of groups before and after curing.

2.3.2. Gel Fraction and Swelling Degree Analyses. Gel fraction and swelling degree analyses of coating product are conducted in Soxhlet tool in accordance with the ASTM (American Society for Testing and Materials) D 2765 [51]. Briefly, the dried coating was immersed in acetone solution for $24 \mathrm{~h}$; then, the insoluble portion was dried at $50^{\circ} \mathrm{C}$. The gel fraction is a weight ratio of insoluble portion and the initial coating. 
<smiles>C=C(C)C(=O)OCC(O)COc1ccc(C(C)(C)c2ccc(OCC(O)COC(=O)C(=C)C)cc2)cc1</smiles><smiles>C=CC(=O)OCCOC(=O)C=C</smiles>

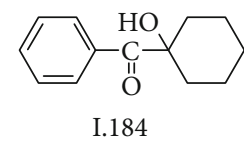

Figure 1: Chemical formula of Bisphenol A glycerolate dimethacrylate (BGDM), 1,6-hexanediol diacrylate (HDDA), and 1-hydroxy-cyclohexyl-phenyl-ketone (I.184).

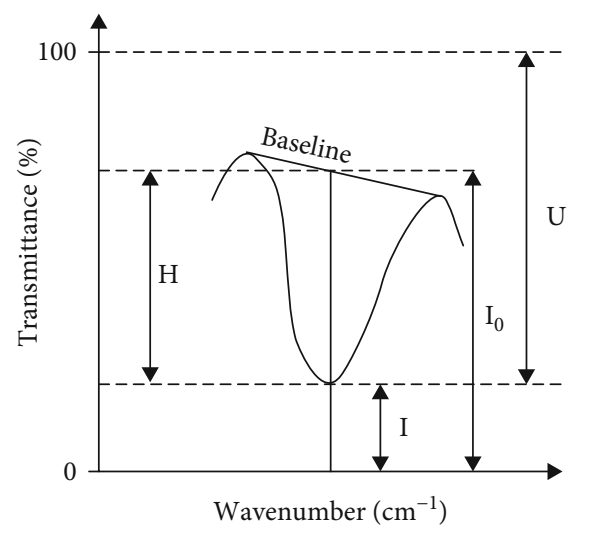

Figure 2: The relationship between $I_{0}$ and $I$ with $H$ and $U$.

Similarity, the swelling degree is a weight ratio of swollen film and the dried film.

\subsubsection{Determination of Mechanical Resistance and Surface} Morphology. The value of coating abrasion resistance was calculated by using abrasive falling methods, according to the ASTM D968 [28]. The value of relative hardness was determined on a Pendulum Damping Tester, model 300, according to the Persoz Standard, model NF T 30-016. It was calculated by the following equation:

The relative hardness $=\frac{\text { absolute hardness of coating }}{425(425 \text { was absolute hardness of standard glass })}$.

The surface chemistry was observed in a scanning electron microscope (SEM-S-4800, Hitachi, Japan). To increase the electrical conductivity of products, their surface was covered by a carbon layer.

2.3.4. Thermal Analysis. Thermogravimetry experiments were performed using a well-equipped thermogravimetry analyzer (TGA-50, Shimadzu, Japan). The samples were heated in ranged of $25-600^{\circ} \mathrm{C}$, at a rate of $10^{\circ} \mathrm{C} \mathrm{min}^{-1}$ (under an argon atmosphere with a flow rate of $50 \mathrm{~cm}^{3} \mathrm{~min}^{-1}$ ).

\section{Results and Discussions}

3.1. IR Spectra Studies. IR spectra measurement has been used widely to evaluate the crosslinking process of UV-curable acrylate epoxy coating, thought the chemical conversion of acrylate double bonds [51,52]. Figure 3 shows the IR spectra of the neat UV curing acrylate epoxy coating (UVAE) and the nanocomposite coating with 2.5 wt. $\%$ nano- $\mathrm{SiO}_{2}\left(\mathrm{UVAE} / \mathrm{SiO}_{2}\right)$ before and after $9.6 \mathrm{~s}$ UV light exposure.

As shown in Figure 3, a decrease in intensity of the characteristic peaks $\left(1636,1409,983\right.$, and $\left.812 \mathrm{~cm}^{-1}\right)$ for $=\mathrm{C}-\mathrm{H}$ stretching vibrations in acrylate groups was clearly observed after $9.6 \mathrm{~s}$ of UV exposure. Besides, the absorbance intensity of $1510 \mathrm{~cm}^{-1}$ band (=C-H stretching of aromatic ring) did not change after UV light exposure [51]. The peaks at 983 and $1510 \mathrm{~cm}^{-1}$ changed clearly but not overlapped with the neighboring bands. Therefore, the peak at $983 \mathrm{~cm}^{-1}$ was chosen to quantitatively evaluate the variation of the acrylate group during UV light irradiation exposure, whereas peaks at $1510 \mathrm{~cm}^{-1}$ can be used as the reference. Conversion of acrylate double bonds in the neat coating (UVAE) and the nanocomposite containing $2.5 \mathrm{wt} \%$ nano- $\mathrm{SiO}_{2}$ (UVAE/$\mathrm{SiO}_{2}$ ) during the UV light exposure process is presented in Figure 4. For the comparative study, we also added the conversion of acrylate double bonds in the acrylate urethane coating (UVAU) [50] in Figure 4.

As can be observed in Figure 4, the acrylate double bonds are conversed rapidly in the first $0.3 \mathrm{~s}$ of UV light exposure, and their conversion rate is reduced till $9.6 \mathrm{~s}$ of UV light exposure. Conversion of acrylate double bonds in the neat coating was higher than that in the nanocomposite. After $4.8 \mathrm{~s}$ of UV exposure, content of acrylate group conversed 87.3 and $81.6 \%$ in the neat coating and the nanocomposite, respectively. Further exposure to UV light irradiation could only improve slightly the conversion of acrylate double bonds. After $9.6 \mathrm{~s}$ of UV exposure, the content of acrylate groups conversed 89.4 and $85.0 \%$ in the neat coating and the nanocomposite, respectively.

It was reported in the literature that the photoinitiator was very sensitive to UV radiation $[2,51,52]$. Under UV light from a medium-pressure mercury lamp, photoinitiator I.184 was decomposed into the free radicals. Then, these free radicals reacted with acrylate double bonds, thus initiated photo-crosslinking polymerization reaction. Briefly, in the first $0.15 \mathrm{~s}$ of UV exposure, the content of photoinitiators was high (around 3\%), and the curing system was relatively flexible (low viscosity). Therefore, the reaction of the acrylate double bonds was insignificantly affected by UV absorbers; however, the concentration of the photoinitiators and acrylate double bonds was reduced rapidly; thus, the conversion of the acrylate double bonds decreased.

This finding can be explained by the fact that nano$\mathrm{SiO}_{2}$ absorbed the UV light $[20,49,50]$, leading to protect the photoinitiators from photon absorption. On the other hand, the conjugated double bonds of the benzene ring in BGDM that strongly absorb in the $270 \mathrm{~nm}$ wavelength region also prevent the UV energy absorption of the photoinitiators, which is a reason why the conversion performance of acrylate groups in this coating system (UV 


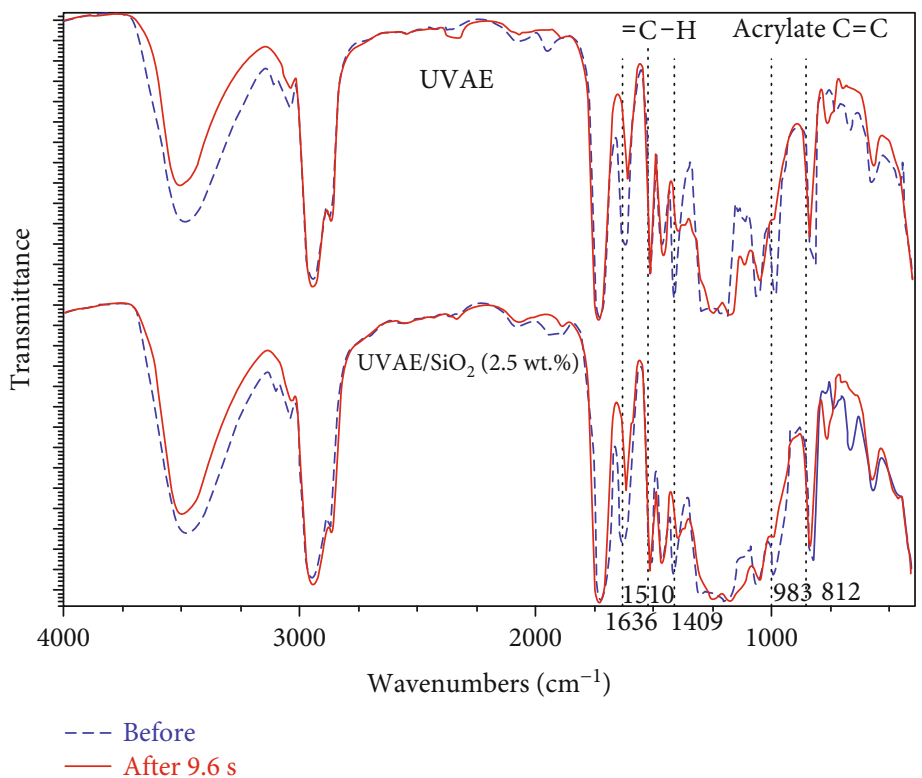

FIGURE 3: IR spectra of the neat UV curing acrylate epoxy coating (UVAE) and the nanocomposite $\left(U V A / S_{\mathrm{i}} \mathrm{O}_{2}\right.$ ) before and after $9.6 \mathrm{~s}$ of UV light exposure.

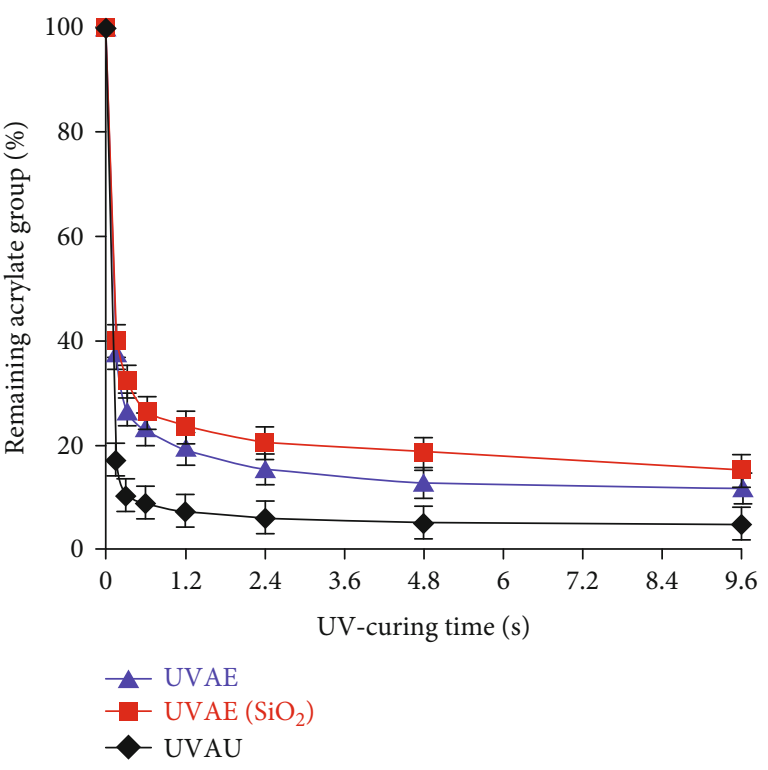

Figure 4: Conversation of acrylate double $2.5 \mathrm{wt} . \% \quad \mathrm{~S}_{\mathrm{i}} \mathrm{O}_{2}$ (UVAE/ $/ \mathrm{S}_{\mathrm{i}} \mathrm{O}_{2}$ ) during the UV exposure process.

curing acrylic epoxy resin) was lower than that in the UV curing acrylate urethane resin [52].

3.2. Gel Fraction and Swelling Degree Studies. Gel fraction and swelling degree were important parameters to evaluate the crosslinking of the thermoset resin. Figure 5 presents the variations of gel fraction and swelling degree of the neat coating and the nanocomposite with $2.5 \mathrm{wt} . \%$ nano- $\mathrm{SiO}_{2}$ during the UV light exposure process. As shown, after $0.3 \mathrm{~s}$ of the reaction, the gel fraction of the coatings without and with
$2.5 \mathrm{wt} . \%$ nano- $\mathrm{SiO}_{2}$ appeared. The gel fraction increased, and the swelling degree reduced rapidly in the first $2.4 \mathrm{~s}$, and after then, it slowed down. In the presence of $2.5 \mathrm{wt}$. $\%$ nano- $\mathrm{SiO}_{2}$, the gel fraction decreased insignificantly, while its swelling degree increased slightly. After $4.8 \mathrm{~s}$ of the reaction, the gel fraction and swelling degree reached the maximum values of 95.5 and 365.2 (for the neat coating) and 95.0 and $380.4 \%$ (for the nanocomposite), respectively.

Thus, nano- $\mathrm{SiO}_{2}$ did not affect to the gel fraction but affected slightly on the swelling of the coating. This obtained data could be explained by the fact that UV-absorbing nano$\mathrm{SiO}_{2}$ reduced the conversion efficiency of acrylate groups and did not significantly affect on the curing participation of BGDM resin and HDDA diluent but reduced slightly the crosslinking density of the coating so the gel fraction of the coating changed insignificantly, while its swelling increased slightly.

3.3. Coating Hardness Study. For thermoset resin systems, monitoring the hardness of system is also a simple and effective method to study the kinetics of curing reaction because during curing the resin system gradually changes from liquid to solid state and becomes stiffer over time. The changes in relative hardness of the neat coating and the nanocomposite containing 2.5 wt. $\%$ nano- $\mathrm{SiO}_{2}$ during exposure to UV light radiation are presented in Figure 6. As can be seen in Figure 6 , the hardness of the coatings increased rapidly in the first 1.2 UV exposure and then slowed down. After 4.8 seconds of the exposure, the hardness of the neat coating and the nanocomposite coating reached the maximum values of 0.91 and 0.89 , respectively. The hardness of the coatings was not much different. The enhanced hardness of the coatings in the first stage of UV light exposure can be explained by the fast curing rate, due to the higher 


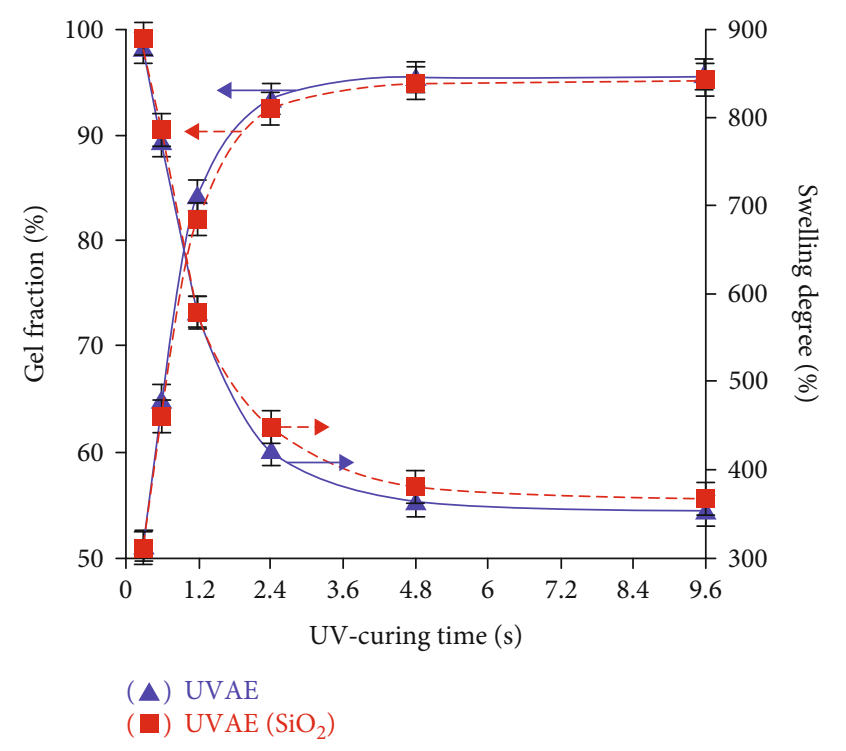

FIGURE 5: Variation of gel fraction and swelling degree of the neat coating (UVAE) and the nanocomposite with $2.5 \mathrm{wt} . \%$ nano- $\mathrm{S}_{\mathrm{i}} \mathrm{O}_{2}$ during the UV exposure process.

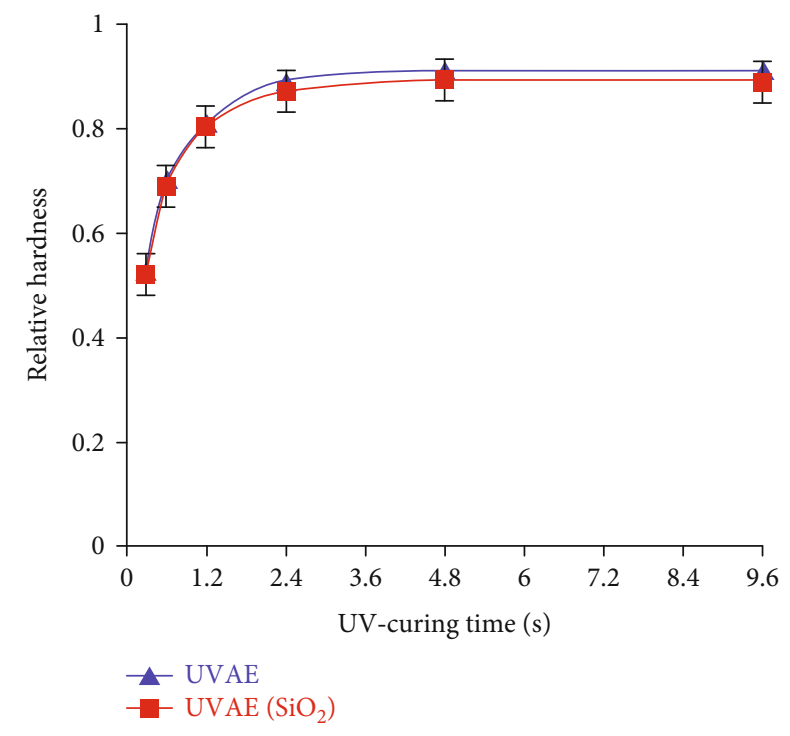

FIGURE 6: Variation of relative hardness of the neat coating (UVAE) and the nanocomposite with $2.5 \mathrm{wt} . \%$ nano- $\mathrm{S}_{\mathrm{i}} \mathrm{O}_{2}$ during the UV light exposure.

concentrations of initiator and the acrylate group, as well as the higher coating flexibility. However, after $1.2 \mathrm{~s}$ of UV exposure, the initiator concentration was not much and the most of the acrylate double bonds has converted as well as the coatings were less flexible due to the high crosslinking density as shown in Figures 4 and 5 so the reaction rate slowed down resulting to that the hardness of the coatings increased also slowly.

Addition of $2.5 \mathrm{wt} . \%$ nano- $\mathrm{SiO}_{2}$ into the coating matrix can make their structure became harder. However, it could

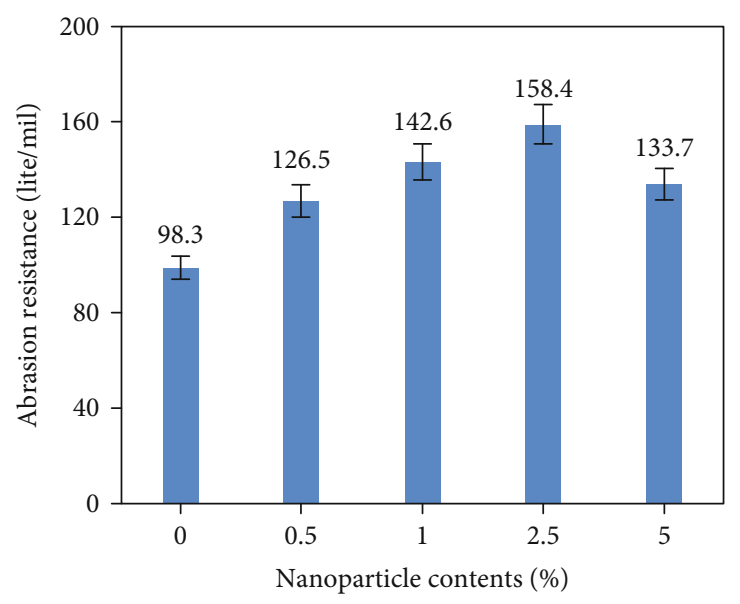

FIgURE 7: Influence of nano- $\mathrm{S}_{\mathrm{i}} \mathrm{O}_{2}$ on the abrasion resistance of the coating.

also reduce the coating hardness due to the higher roughness of coating surface. These two contradictory impacts might compete with each other, leading to the slight variation in the coating hardness [51].

3.4. Coating Abrasion Resistance Study. $\mathrm{SiO}_{2}$ nanoparticles have been used widely as nanofillers to enhance the abrasive resistance of polymer materials, due to their high hardness and abrasion resistance [49]. Figure 7 presents the effect of nano- $\mathrm{SiO}_{2}$ contents on the abrasion resistance of the nanocomposite coating. As can be observed in Figure 7, abrasion resistance of the nanocoating increased with increasing the content of nano- $\mathrm{SiO}_{2}$ (from 0 to $2.5 \mathrm{wt} . \%$ ). In the introduction of $2.5 \mathrm{wt} . \%$ nanoparticles into the polymer matrix, the abrasion resistance of the coating increased $60 \%$ (from 98.3 to 158.4 lite/mil). However, when $5 \mathrm{wt} . \%$ nanoparticles were used, the abrasion resistance of the nanocoating was only 133.7 lite/mile (36\% increase). Figure 8 was TEM (a) and FESEM (b) images of $\mathrm{SiO}_{2}$ nanoparticles and the FESEM images of nanocomposite coatings with $2.5 \mathrm{wt} . \%$ and 5 wt.\% of $\mathrm{SiO}_{2}$ nanoparticles. Figures $8(\mathrm{a})$ and $8(\mathrm{~b})$ present the FESEM and TEM images of $\mathrm{SiO}_{2}$ nanoparticles. As can be seen in these figures, the average size of nano- $\mathrm{SiO}_{2}$ is about $15 \mathrm{~nm}$. Figures $8(\mathrm{c})$ and $8(\mathrm{~d})$ are the FESEM images of nanocomposite coatings containing 2.5 and $5 \mathrm{wt} \%$ of nanoparticles, respectively. In case that the content of nano- $\mathrm{SiO}_{2}$ is 2.5 wt.\%, FESEM image indicates that $\mathrm{SiO}_{2}$ nanoparticles are homogeneously dispersed into the coatings (Figure 8(c)). In this case, these small nanoparticles could not only serve as nanofillers for the polymer matrix, but also actively participate in the polymer-curing process. We expect that these small nanoparticles can penetrate into small holes/indentation/capillaries in the polymer matrices and also can act as nuclei for the growth of crosslinking polymer networks. In case that the content of nano- $\mathrm{SiO}_{2}$ is $2.5 \mathrm{wt} . \%$ is used, large aggregations $(\sim 0.5 \mu \mathrm{m}$ in size $)$ were found in the nanocomposite coating (Figure 8(d)). These aggregations might lead to reduce the mechanical property of the nanocomposite coating. 


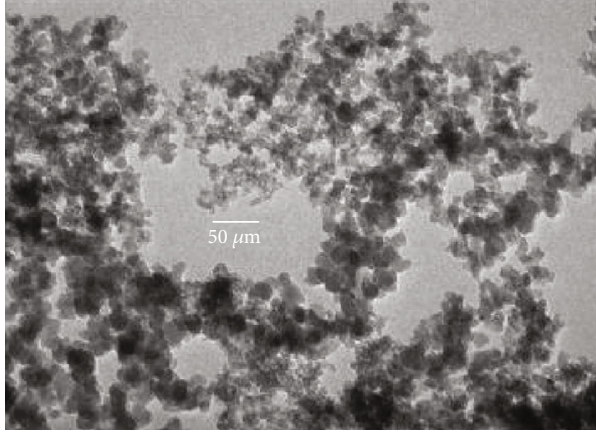

(a)

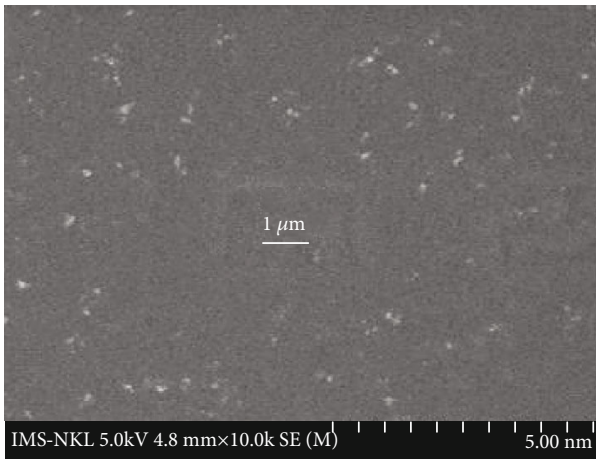

(c)

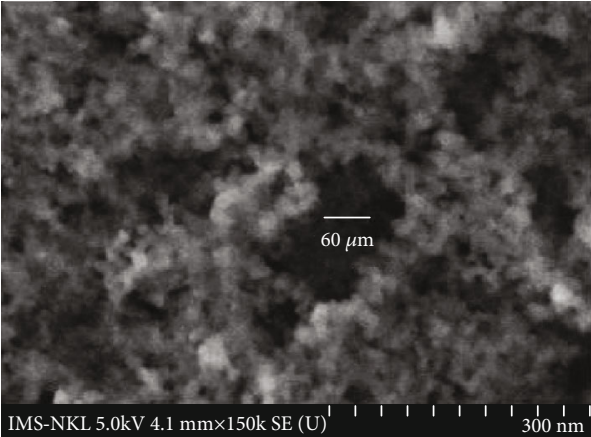

(b)

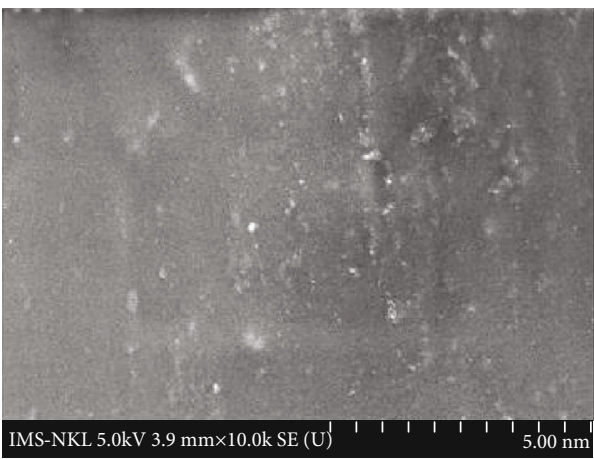

(d)

Figure 8: (a) TEM and (b) FESEM images of $\mathrm{S}_{\mathrm{i}} \mathrm{O}_{2}$ nanoparticles and FESEM images of nanocomposite containing (c) 2.5 wt.\% and (d) 5 wt.\% nano- $\mathrm{S}_{\mathrm{i}} \mathrm{O}_{2}$.

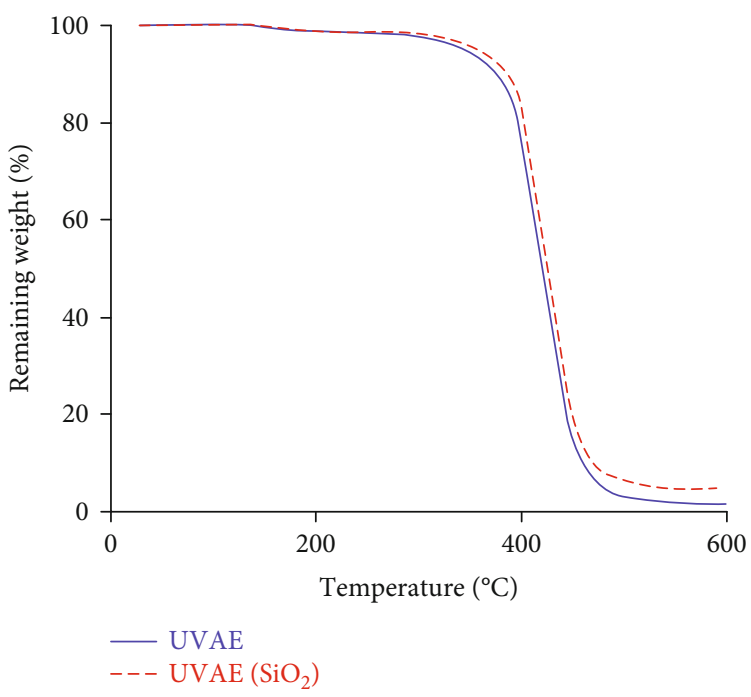

FIgURE 9: TGA curves of the neat coating and the nanocomposite coatings.

3.5. Study on Thermal Stability of Coating. Figure 9 is TGA curves of the neat coating and the nanocomposite coating with 2.5 wt. $\%$ nano- $\mathrm{SiO}_{2}$. Table 1 shows the values of temperature at the weight loss of $5 \%, 50 \%$, and $75 \%$ for the coating samples. The data from Figure 9 and Table 1 showed that the initial loss stage of the coatings with weight loss of $5 \%$ was observed around $345-360^{\circ} \mathrm{C}$. The possible reason could be attributed to the release of both adsorbed water and low molecular organic substances. The $T_{5 \%}\left(T_{\text {initial }}\right)$ of the neat coating and the nanocomposite with $2.5 \mathrm{wt} \%$ nano- $\mathrm{SiO}_{2}$ were 348 and $357^{\circ} \mathrm{C}$. The $T_{5 \%}$ increase of the coating $\left(9^{\circ} \mathrm{C}\right)$ due to the presence of the nanoparticles could be interpreted in the terms of their role as thermal stabilizers. The stage of major weight loss of $50 \%$ occurred at 
TABLE 1: Values of $T_{5 \%}, T_{50 \%}$, and $T_{75 \%}$ for the neat and nanocomposite coatings.

\begin{tabular}{lccc}
\hline Coatings & $T_{5 \%}\left({ }^{\circ} \mathrm{C}\right)$ & $T_{50 \%}\left({ }^{\circ} \mathrm{C}\right)$ & $T_{75 \%}\left({ }^{\circ} \mathrm{C}\right)$ \\
$(5 \%$ loss in mass $)$ & $(50 \%$ loss in mass $)$ & $45 \%$ loss in mass $)$ \\
\hline UVAE & 348 & 420 & 440 \\
UVAE $/ \mathrm{S}_{\mathrm{i}} \mathrm{O}_{2}$ & 357 & 425 & 445 \\
\hline
\end{tabular}

$420^{\circ} \mathrm{C}$ for the neat coating, and at $425^{\circ} \mathrm{C}$ for the nanocomposite was attributed to scission of backbone chain $[25,28]$ in acrylate urethane polymer matrix. The coatings lost $75 \%$ of its weight at the temperature of $440^{\circ} \mathrm{C}$ for the neat coating and $445^{\circ} \mathrm{C}$ for the nanocomposite.

As compared to the styrene acrylic polyurethane and acrylic emulsion coatings $[25,28]$, thermal stability of this nanocomposite coatings is higher. This finding can be explained by the higher crosslinking density and higher thermal resistance chemical bonds in this nanocomposite.

\section{Conclusions}

The effect of $\mathrm{SiO}_{2}$ nanoparticles on the photo-crosslinking polymerization process of UV-curable acrylate epoxy system has been evaluated. Microstructure and properties of the UV curing acrylic epoxy/SiO $\mathrm{S}_{2}$ nanocomposite coating are also characterized.

The main findings of this study were as follows:

(i) FESEM images indicated that $\mathrm{SiO}_{2}$ nanoparticles were homogeneously dispersed into the coatings, when used at the content of $2.5 \mathrm{wt} . \%$. However, large aggregations were found in the nanocomposite coating with 5 wt. $\%$ nano- $\mathrm{SiO}_{2}$

(ii) In the photo-crosslinking polymerization process, FTIR data indicated that nanoparticle reduced the conversion performance of acrylate double bonds, thus slightly increased the swelling degree of nanocomposite coating

(iii) Incorporation of $\mathrm{SiO}_{2}$ nanoparticles into the coating matrix (as nanofillers, at content of $2.5 \mathrm{wt} . \%$ ) enhanced significantly its abrasion resistance and thermal stability by $60 \%$ (from 98.3 to 158.4 lite/mil) and $9^{\circ} \mathrm{C}$ (from $348^{\circ} \mathrm{C}$ to $357^{\circ} \mathrm{C}$ ), respectively

(iv) In the UV curing acrylic epoxy/SiO${ }_{2}$ nanocomposite coating, $\mathrm{SiO}_{2}$ nanoparticles can play dual roles, as both UV absorbers and nanoreinforcers

\section{Data Availability}

All the data and supporting materials are included within the article.

\section{Conflicts of Interest}

All authors declare that there are no conflicts of interest regarding the publication of this paper.

\section{Acknowledgments}

The paper is financially supported by the Graduate University of Science and Technology, Vietnam Academy of Science and Technology (GUST.STS.ĐT 2020-HH06).

\section{References}

[1] M. de Brito, X. Allonas, C. Croutxé-Barghorn, M. Palmieri, and I. Alig, "Kinetic study of photoinduced quasisimultaneous interpenetrating polymer networks," Progress in Organic Coatings, vol. 73, no. 2-3, pp. 186-193, 2012.

[2] P. Nguyen-Tri, "Thien Vuong Nguyen, Radically Curable Nanobased Coatings (chapter 10)," in Nanomaterials Based Coatings, P. N. Tri, S. Rtimi, and C. Ouellet-Plamondon, Eds., pp. 339-372, Elsevier, 2019.

[3] L. X. Hien, N. T. Vuong, L. M. Thuy, and N. T. V. Trieu, "Study of photocrosslinking reaction of the resin system on the base of copolymer of tung and soyabean oils, methyl methacrylate, styrene," Journal of Science and Technology, vol. 48, no. 3A, pp. 150-157, 2010.

[4] N. T. Vuong, Đ. P. Hung, N. A. Hiep, M. Van Phuc, T. Van Thanh, and Đ. T. Lien, "Degradation of Primal AC-261 acrylic emulsion in the artificial weathering environment," Journal of Science and Technology, vol. 53, no. 3, pp. 317-321, 2015.

[5] T. V. Nguyen, X. H. Le, P. H. Dao, C. Decker, and T. P. Nguyen, "Stability of acrylic polyurethane coatings under accelerated aging tests and natural outdoor exposure: the critical role of the used photo-stabilizers," Progress in Organic Coatings, vol. 124, pp. 137-146, 2018.

[6] M. Sangermano, W. Carbonaro, G. Malucelli, and A. Priola, "UV-cured interpenetrating acrylic epoxy polymer networks: preparation and characterization," Macromolecular Materials and Engineering, vol. 293, no. 6, pp. 515-520, 2008.

[7] C. Rocco, F. Karasu, C. Croutxé-Barghorn, X. Allonas, and G. de With, "Highly-interpenetrated and phase-separated UV-cured interpenetrating methacrylate-epoxide polymer networks: influence of the composition on properties and microstructure," Materials Today Communications, vol. 6, pp. 17-27, 2016.

[8] T. A. T. Canellas, A. de Almeida Neves, I. K. B. dos Santos, A. R. P. de Rezende, and E. M. da Silva, "Characterization of low-shrinkage dental composites containing methacrylethylpolyhedral oligomeric silsesquioxane (ME-POSS)," Journal of the Mechanical Behavior of Biomedical Materials, vol. 90, pp. 566-574, 2019.

[9] S. Garoushi, P. K. Vallittu, D. C. Watts, and L. V. J. Lassila, "Effect of nanofiller fractions and temperature on polymerization shrinkage on glass fiber reinforced filling material," Dental Materials, vol. 24, no. 5, pp. 606-610, 2008.

[10] M. Tafesse and H.-K. Kim, "The role of carbon nanotube on hydration kinetics and shrinkage of cement composite," Composites Part B: Engineering, vol. 169, no. 15, pp. 55-64, 2019. 
[11] B. Pratap, R. K. Gupta, B. Bhardwaj, and M. Nag, "Modeling based experimental investigation on polymerization shrinkage and micro-hardness of nano alumina filled resin based dental material," Journal of the Mechanical Behavior of Biomedical Materials, vol. 99, pp. 86-92, 2019.

[12] S.-J. Lee, S. Kawashima, K.-J. Kim, S.-K. Woo, and J.-P. Won, "Shrinkage characteristics and strength recovery of nanomaterials-cement composites," Composite Structures, vol. 202, no. 15, pp. 559-565, 2018.

[13] D. Kumar, K. D. B. Yamajala, A. B. Samui, and S. Banerjee, "Tailoring of energetic groups in acroyloyl polymers," Designed Monomers and Polymers, vol. 20, no. 1, pp. 332343, 2017.

[14] D. Kumar, H. Singh, M. Maurya et al., "Novel evaluation enhancement role of poly (1-(3-nitrophenyl)-1H-1, 2, 3-triazol-4-yl) acrylate materials for propellant composite formulation," Materials Letters, vol. 280, p. 128585, 2020.

[15] S. Singh, A. Singh, V. S. S. Bais, B. Prakash, and N. Verma, "Multi-scale carbon micro/nanofibers-based adsorbents for protein immobilization," Materials Science and Engineering: C, vol. 38, pp. 46-54, 2014.

[16] S. Singh, A. Modi, and N. Verma, "Enhanced power generation using a novel polymer-coated nanoparticles dispersedcarbon micro-nanofibers-based air-cathode in a membraneless single chamber microbial fuel cell," International Journal of Hydrogen Energy, vol. 41, pp. 1237-1247, 2016.

[17] A. Pophali and N. V. ShivSingh, "Simultaneous hydrogen generation and COD reduction in a photoanode-based microbial electrolysis cell," International Journal of Hydrogen Energy, vol. 45, no. 48, pp. 25985-25995, 2020.

[18] T. A. Nguyen, T. H. Nguyen, T. V. Nguyen, H. Thai, and X. Shi, "Effect of nanoparticles on the thermal and mechanical properties of epoxy coatings," Journal of Nanoscience and Nanotechnology, vol. 16, pp. 9874-9881, 2016.

[19] P. H. Dao, T. V. Nguyen, M. H. Dang et al., "Effect of silica nanoparticles on properties of coatings based on acrylic emulsion resin," Vietnam Journal of Science and Technology, vol. 56, no. 3B, pp. 117-125, 2018

[20] T. V. Nguyen, T. A. Nguyen, and T. H. Nguyen, "The synergistic effects of $\mathrm{SiO} 2$ nanoparticles and organic photostabilizers for enhanced weathering resistance of acrylic polyurethane coating," Journal of Composites Science, vol. 4, no. 1, p. 23, 2020.

[21] T. V. Nguyen, P. H. Dao, T. A. Nguyen et al., "Photocatalytic degradation and heat reflectance recovery of water-borne acrylic polymer/ZnO nanocomposite coating," Journal of Applied Polymer Science, vol. 137, no. 37, article e49116, 2020.

[22] V. Tien Viet, T. V. Nguyen, M. Tabish et al., "Water-borne $\mathrm{ZnO} /$ acrylic nanocoating: fabrication, characterization, and properties," Polymers, vol. 13, no. 5, p. 717, 2021.

[23] T. V. Nguyen, P. H. Dao, K. L. Duong et al., "Effect of R-TiO2 and $\mathrm{ZnO}$ nanoparticles on the UV-shielding efficiency of water-borne acrylic coating," Progress in Organic Coatings, vol. 110, pp. 114-121, 2017.

[24] T. V. Nguyen, T. P. Nguyen, T. D. Nguyen, R. Aidani, V. T. Trinh, and C. Decker, "Accelerated degradation of water borne acrylic nanocomposites used outdoor protective coatings," Polymer Degradation and Stability, vol. 128, pp. 65-76, 2016.

[25] P. H. Dao, T. V. Nguyen, T. A. Nguyen et al., "Acrylic polymer/TiO2 nanocomposite coatings: mechanism for photodegradation and solar heat reflective recovery," Materials Chemistry and Physics, vol. 272, article 124984, 2021.
[26] T. V. Nguyen, T. A. Nguyen, P. H. Dao et al., "Effect of rutile titania dioxide nanoparticles on the mechanical property, thermal stability, weathering resistance and antibacterial property of styrene acrylic polyurethane coating," Advances in Natural Sciences: Nanoscience and Nanotechnology, vol. 7, no. 4, pp. 045015-045024, 2016.

[27] M. Jouyandeh, N. Rahmati, E. Movahedifar et al., "Properties of nano-Fe3O4 incorporated epoxy coatings from Cure Index perspective," Progress in Organic Coatings, vol. 133, pp. 220228, 2019.

[28] T. T. Le, T. V. Nguyen, T. A. Nguyen et al., "Thermal, mechanical and antibacterial properties of water-based acrylic polymer/SiO2-Ag nanocomposite coating," Journal of Materials Chemistry and Physics, vol. 232, pp. 362-366, 2019.

[29] T. D. Ngo, T. M. H. le, T. H. Nguyen et al., "Antibacterial Nanocomposites Based on Fe3O4-Ag Hybrid Nanoparticles and Natural Rubber-Polyethylene Blends," International Journal of Polymer Science, vol. 2016, Article ID 7478161, 9 pages, 2016.

[30] T. N. L. Nguyen, T. V. Do, T. V. Nguyen et al., “Antimicrobial activity of acrylic polyurethane/Fe3O4-Ag nanocomposite coating," Progress in Organic Coatings, vol. 132, pp. 15-20, 2019.

[31] A. Allahverdi, M. Ehsani, H. Janpour, and S. Ahmadi, "The effect of nanosilica on mechanical, thermal and morphological properties of epoxy coating," Progress in Organic Coatings, vol. 75, no. 4, pp. 543-548, 2012.

[32] X. Shi, T. A. Nguyen, Z. Suo, Y. Liu, and R. Avci, "Effect of nanoparticles on the anticorrosion and mechanical properties of epoxy coating," Surface and Coatings Technology, vol. 204, no. 3, pp. 237-245, 2009.

[33] E. Amerio, P. Fabbri, G. Malucelli, M. Messori, M. Sangermano, and R. Taurino, "Scratch resistance of nanosilica reinforced acrylic coatings," Progress in Organic Coatings, vol. 62, no. 2, pp. 129-133, 2008.

[34] F. Bauer, R. Flyunt, K. C. H. Langguth, R. Mehnert, R. Schubert, and M. R. Buchmeiser, "UV curing and matting of acrylate coatings reinforced by nano-silica and microcorundum particles," Progress in Organic Coatings, vol. 60, no. 2, pp. 121-126, 2007.

[35] S. Maganty, M. P. C. Roma, S. J. Meschter et al., "Enhanced mechanical properties of polyurethane composite coatings through nanosilica addition," Progress in Organic Coatings, vol. 90, pp. 243-251, 2016.

[36] Y. C. Ching and N. Syamimie, "Effect of nanosilica filled polyurethane composite coating on polypropylene substrate," Journal of Nanomaterials, vol. 2013, Article ID 567908, 8 pages, 2013.

[37] M. U. M. Junaidi, S. A. Haji Azaman, N. N. R. Ahmad et al., "Superhydrophobic coating of silica with photoluminescence properties synthesized from rice husk ash," Progress in Organic Coatings, vol. 111, pp. 29-37, 2017.

[38] A. Madhan Kumar, S. S. Latthe, P. Sudhagar, I. B. Obot, and Z. M. Gasem, "In-situ synthesis of hydrophobic SiO2PMMA composite for surface protective coatings: experimental and quantum chemical analysis," Polymer, vol. 77, pp. 7986, 2015.

[39] G. Wu, J. C. Di Liu, G. Liu, and Z. Kong, "Preparation and properties of super hydrophobic films from siloxanemodified two-component waterborne polyurethane and hydrophobic nano SiO2," Progress in Organic Coatings, vol. 127 , pp. 80-87, 2019. 
[40] S. Ammar, K. Ramesh, I. A. W. Ma, Z. Farah, and A. K. Arof, "Studies on SiO2-hybrid polymeric nanocomposite coatings with superior corrosion protection and hydrophobicity," Surface and Coatings Technology, vol. 324, pp. 536-545, 2017.

[41] H. Chen, X. Zhang, P. Zhang, and Z. Zhang, "Facile approach in fabricating superhydrophobic SiO2/polymer nanocomposite coating," Applied Surface Science, vol. 261, pp. 628-632, 2012.

[42] B. Lin and S. Zhou, "Poly (ethylene glycol)-grafted silica nanoparticles for highly hydrophilic acrylic-based polyurethane coatings," Progress in Organic Coatings, vol. 106, pp. 145154, 2017.

[43] N. Huong, Improvement of Bearing Strength of Laminated Composites by Nanoclay and Z-Pin Reinforcement, [Ph.D. thesis], University of New South Wales, Australia, 2006.

[44] O. Becker, R. Varley, and G. Simon, "Morphology, thermal relaxations and mechanical properties of layered silicate nanocomposites based upon high-functionality epoxy resins," Polymer, vol. 43, no. 16, pp. 4365-4373, 2002.

[45] M. Jouyandeh, M. Shabanian, M. Khaleghi et al., "Acid-aided epoxy-amine curing reaction as reflected in epoxy/Fe3O4 nanocomposites: chemistry, mechanism, and fracture behavior," Progress in Organic Coatings, vol. 125, pp. 384-392, 2018.

[46] M. Jouyandeh, S. M. R. Paran, M. Shabanian et al., "Curing behavior of epoxy/Fe3O4 nanocomposites: a comparison between the effects of bare $\mathrm{Fe} 3 \mathrm{O} 4, \mathrm{Fe} 3 \mathrm{O} 4 / \mathrm{SiO} 2 /$ chitosan and $\mathrm{Fe} 3 \mathrm{O} 4 / \mathrm{SiO} 2 /$ chitosan/imide/phenylalanine-modified nanofillers," Progress in Organic Coatings, vol. 123, pp. 10-19, 2018.

[47] M. R. Saeb, M. Nonahal, H. Rastin et al., "Calorimetric analysis and molecular dynamics simulation of cure kinetics of epoxy/chitosan-modified Fe3O4 nanocomposites," Progress in Organic Coatings, vol. 112, pp. 176-186, 2017.

[48] M. R. Saeb, H. Rastin, M. Shabanian, M. Ghaffari, and G. Bahlakeh, "Cure kinetics of epoxy/ $\beta$-cyclodextrin-functionalized $\mathrm{Fe} 3 \mathrm{O} 4$ nanocomposites: Experimental analysis, mathematical modeling, and molecular dynamics simulation," Progress in Organic Coatings, vol. 110, pp. 172-181, 2017.

[49] H. Yari, S. Moradian, and N. Tahmasebi, “The weathering performance of acrylic melamine automotive clearcoats containing hydrophobic nanosilica," Journal of Coating Technology and Research, vol. 11, no. 3, pp. 351-360, 2014.

[50] T. M. A. Bui, N. T. Vuong, N. T. Mai et al., "Crosslinking mechanism, mechanical properties and weathering degradation of acrylic polyurethane nanocomposite coating reinforced by $\mathrm{SiO} 2$ nanoparticles issued from rice husk ash," Materials Chemistry and Physics, vol. 241, p. 122445, 2020.

[51] N. T. Vuong, D. T. Vy, H. M. Hung et al., "Crosslinking process, mechanical and antibacterial properties of UV-curable acrylate/Fe3O4-Ag nanocomposite coating," Progress in Organic Coatings, vol. 139, article 105325, 2020.

[52] N. T. Vuong, N. T. Phuong, A. Sohrab et al., "The role of organic and inorganic UV-absorbents on photopolymerization and mechanical properties of acrylate-urethane coating," Materials Today Communications, vol. 22, article 100780, 2020 . 